\title{
Supporting Information for: Surfactant adsorption and ion exchange on calcite surfaces
}

Dirk J. Groenendijk* and Johannes N.M. van Wunnik

Shell Global Solutions International B.V., Amsterdam, Grasweg 31, 1031 HW Amsterdam, The Netherlands

\section{Contents}

Characterization of the Estaillades limestone core …........................................................... 2

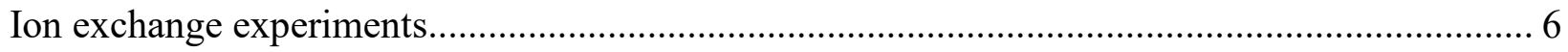

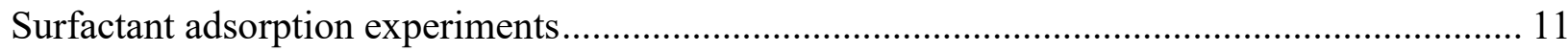

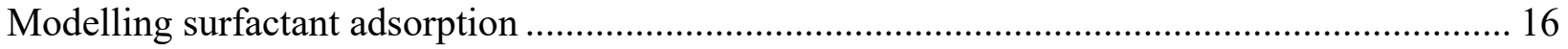

Solution equilibrium reactions and equilibrium constants.............................................. 19 


\section{Characterization of the Estaillades limestone core}

\section{Compositional analysis}

X-ray powder diffraction measurements were performed to determine the composition of the Estaillades limestone outcrop rock. A diffraction measurement is shown in Figure S1, where the theoretical positions of the diffraction peaks of calcite and quartz are indicated by green lines and red arrows, respectively.

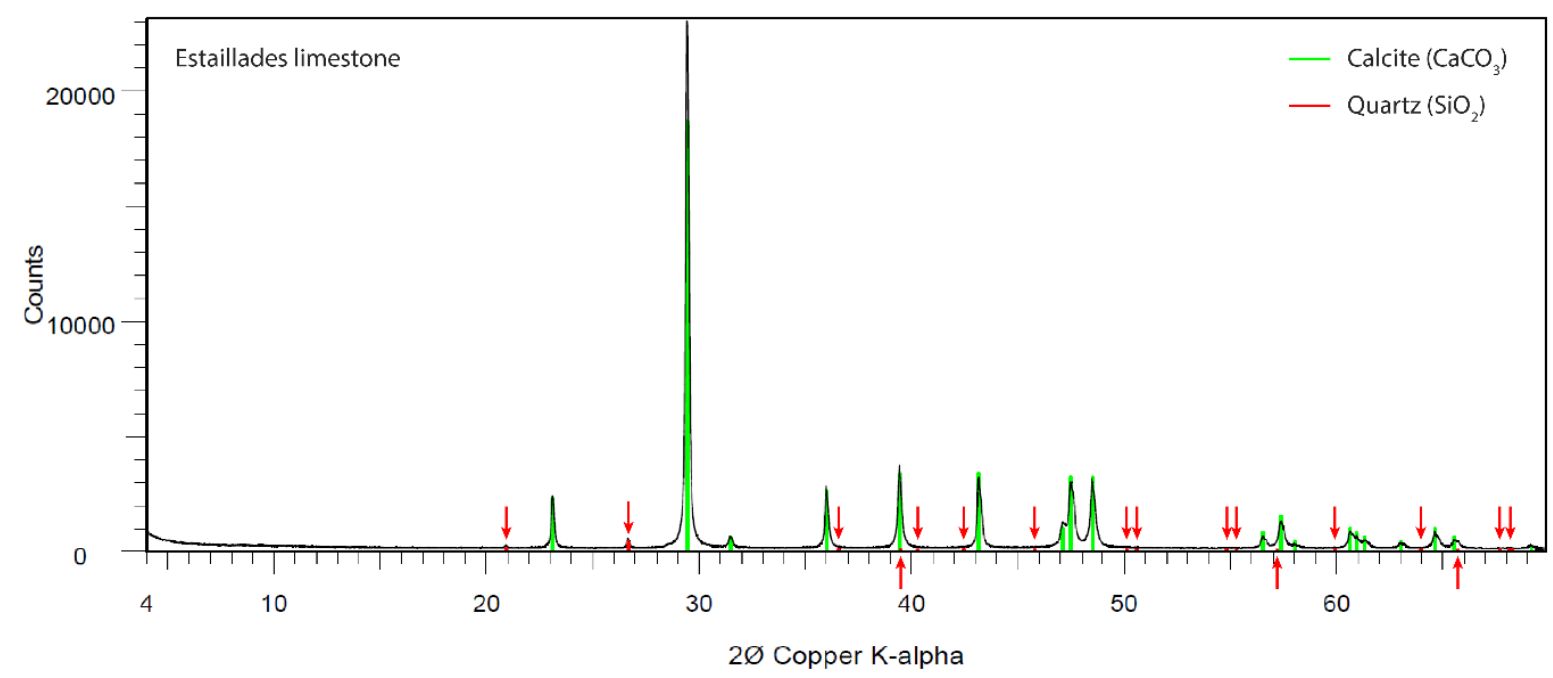

Figure S1. X-ray powder diffraction measurement of Estaillades limestone. The theoretical positions of the diffraction peaks of calcite and quartz are indicated by green and red lines, respectively.

The calculated weight percentages are $99.2 \%$ calcite and $0.8 \%$ quartz. No clay minerals were detected in the bulk analyses, but some were detected in the clay fractions separated after the dissolution of the carbonate matrix by buffered acetic acid. The $<2 \mu \mathrm{m}$ clay fraction is a mixture of illite/smectite mixed-layer clay (71\%), illite (28\%) and possibly a trace (1\%) of chlorite (or berthierine). 


\section{SEM imaging}

An SEM image of the Estaillades limestone rock is shown in Figure S2.

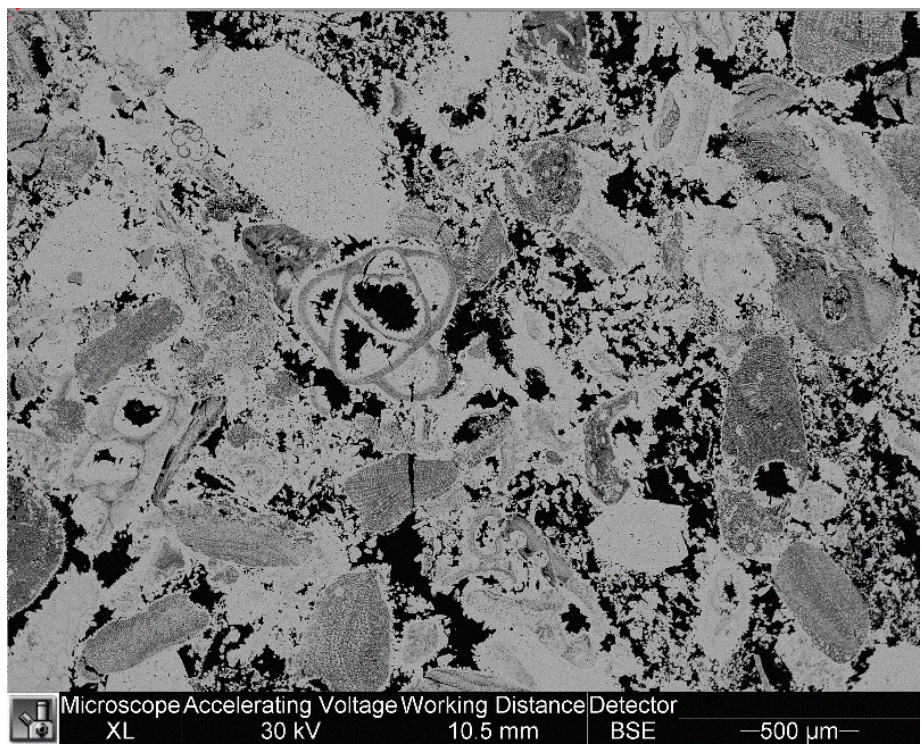

Figure S2. SEM image of Estaillades limestone.

\section{Core properties}

A $30 \mathrm{~cm}$ long, 2" diameter Estaillades limestone core was drilled from an outcrop block and the volumes and porosity was measured. Due to its large size, the bulk volume was determined with a caliper rather than by chloroform buoyancy. The core was not in contact with any chemicals during the preparation except for tap water. After the measurements, the core was dried in a vacuum oven. The properties are listed in Table S1.

\begin{tabular}{|c|c|c|c|c|c|}
\hline $\begin{array}{c}\varphi \\
(\%)\end{array}$ & $\begin{array}{c}\text { Grain density } \\
(\mathrm{g} / \mathrm{ml})\end{array}$ & $\begin{array}{c}\text { Bulk density } \\
(\mathrm{g} / \mathrm{ml})\end{array}$ & $\begin{array}{c}\text { Bulk volume } \\
(\mathrm{ml})\end{array}$ & $\begin{array}{c}\text { Grain volume } \\
(\mathrm{ml})\end{array}$ & $\begin{array}{c}\text { Pore volume } \\
(\mathrm{ml})\end{array}$ \\
\hline 30.4 & 2.705 & 1.884 & 602.681 & 419.716 & 182.965 \\
\hline
\end{tabular}

Table S1. Properties of the Estaillades limestone core. 


\section{CT scans}

Axial and radial CT scans in Figure S3 show that the core is rather homogeneous.
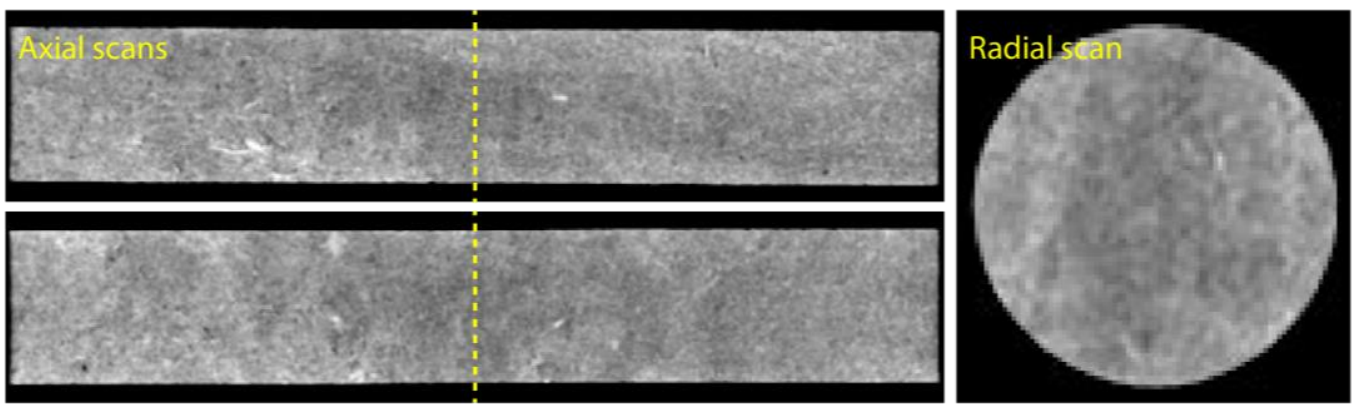

Figure S3. CT scan of core LC14. The radial scan is taken along the centre of the core (dashed line).

\section{Pore throat distribution}

Mercury injection capillary pressure (MICP) measurements show that the pore size distribution is bimodal (see Figure S4).

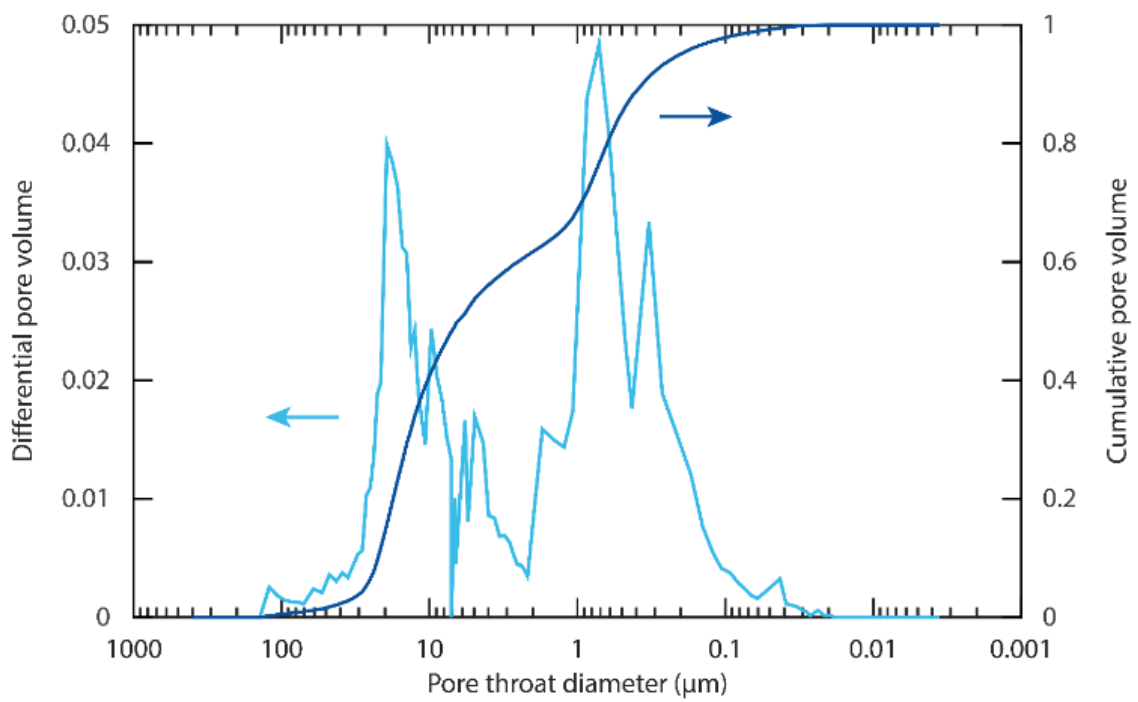

Figure S4. Pore throat size distribution of Estaillades limestone outcrop rock measured by MICP. 


\section{Tracer injection}

Before starting with the adsorption experiments, a $20 \mathrm{ppm}$ KI tracer was injected to characterize the heterogeneity of the core. KI was used because it does not interact with the rock surface through ion exchange reactions and its concentration can be measured with UV-Vis. A 2 PV slug of brine with 20 ppm KI is injected followed by 2 PV brine: the resulting profile is shown in Figure S5. Every point in the graph corresponds to a $5 \mathrm{ml}$ fraction of the effluent of which the absorbance is measured.

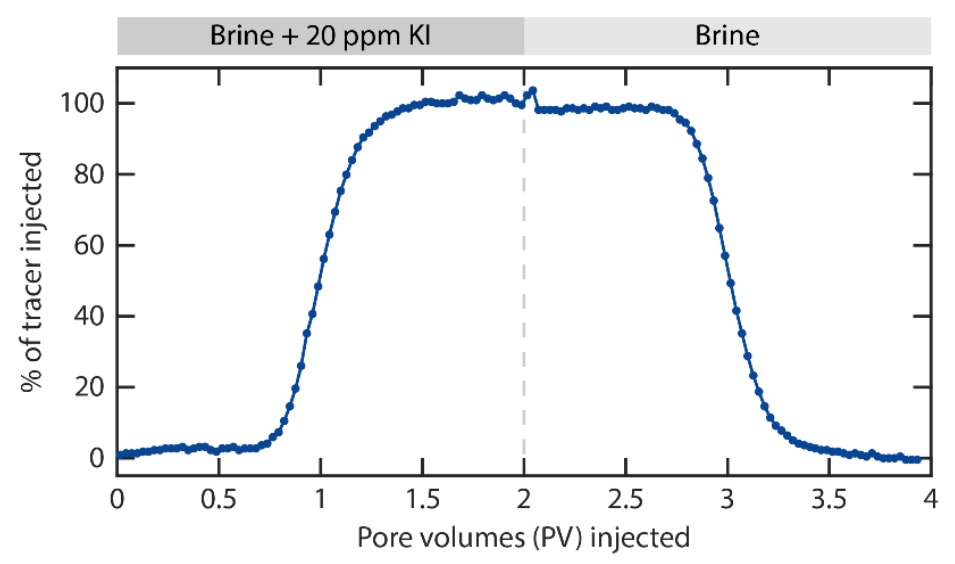

Figure S5. Tracer concentration (expressed as \% of injected concentration) as a function of the number of pore volumes injected.

The tracer concentration reaches $50 \%$ around $1 \mathrm{PV}$, indicating that it does not adsorb to the calcite surface and there is no bypassed volume. 


\section{Ion exchange experiments}

\section{DI - brine injection}

The modelled $\mathrm{Ca}$ concentration and $\mathrm{pH}$ are shown together with the experimental data in Figure $\mathrm{S} 6 \mathrm{a}$ and $\mathrm{b}$. The Mg, Na, and K concentrations are shown in Figure S6c and d.
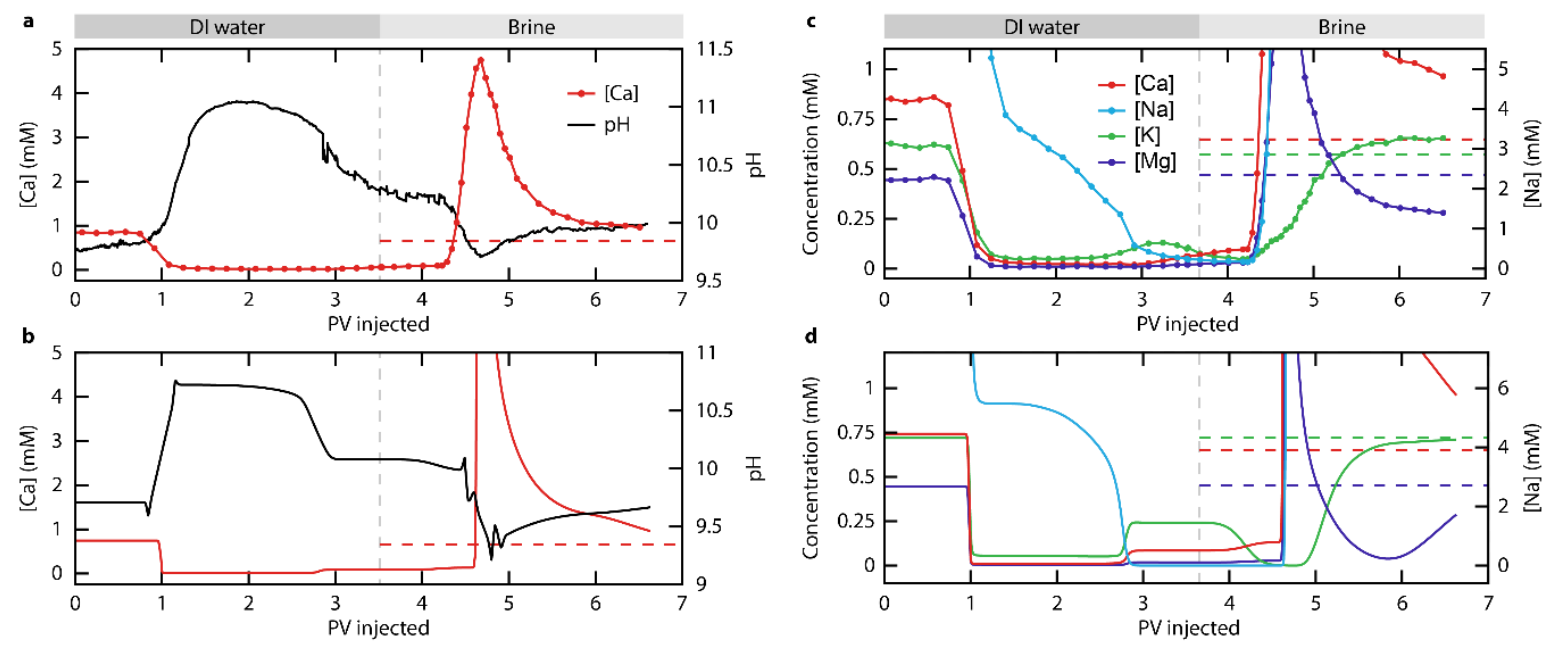

Figure S6. Experimental (a) and modelled (b) Ca concentration and pH values. The modelled pH values have been numerically averaged. Experimental (c) and modelled (d) elemental concentrations. 


\section{Variation of the CEC value}

Figure S7 shows the modelled elemental concentrations during the injection of DI water followed by brine for 3 different CEC values. This parameter reflects the net negative surface charge that is screened in the EDL and determines when the $\mathrm{Na}$ concentration goes to zero and the $\mathrm{Ca}$ and $\mathrm{Mg}$ concentrations start to increase.

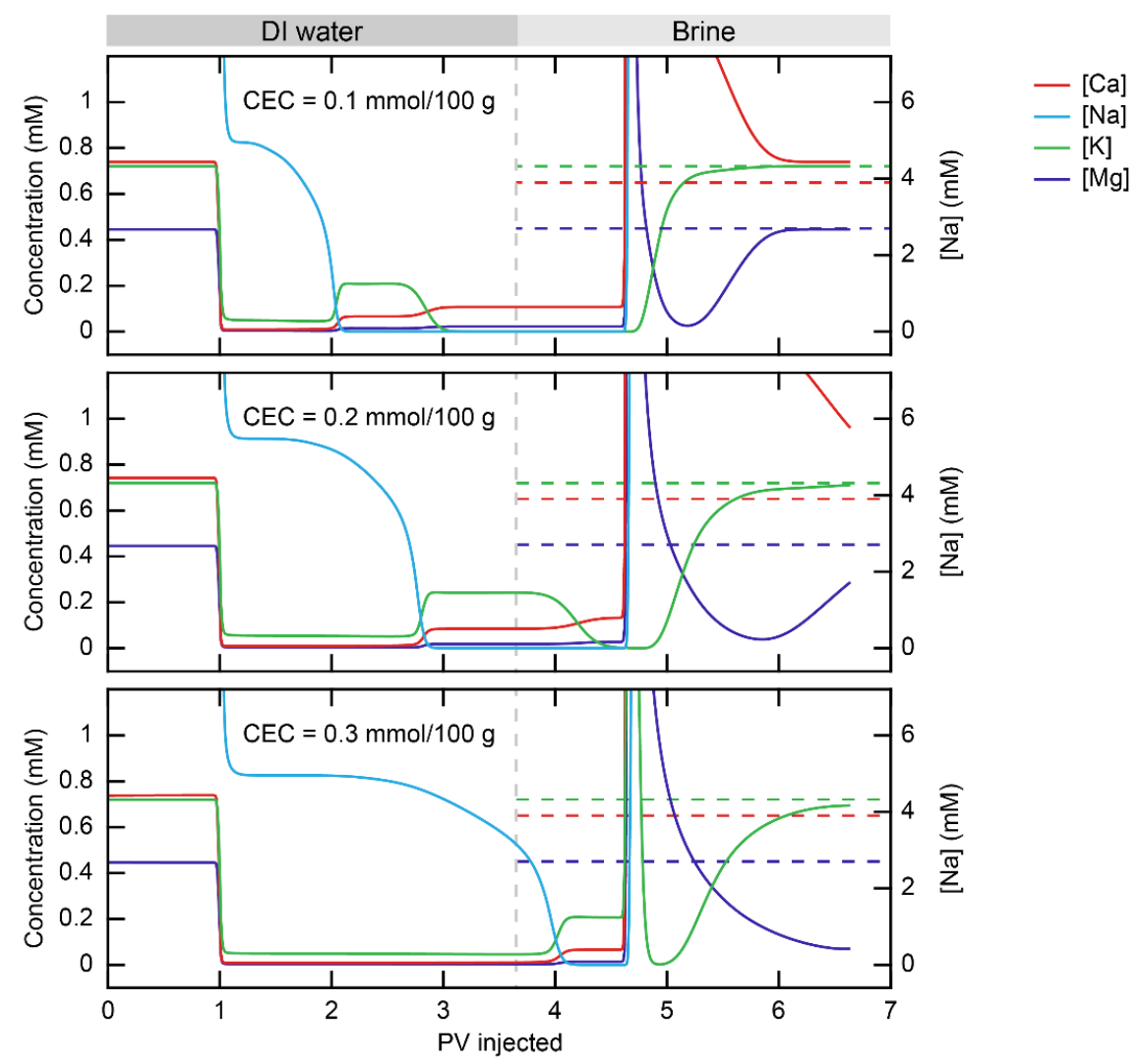

Figure S7. Elemental concentrations during the injection of DI water followed by brine for different CEC values. 


\section{Inclusion of dispersion}

Figure S8 shows the modelled elemental concentrations during the injection of DI water followed by brine for different dispersivity values. The variations in elemental concentrations become more gradual as the dispersivity value is increased.

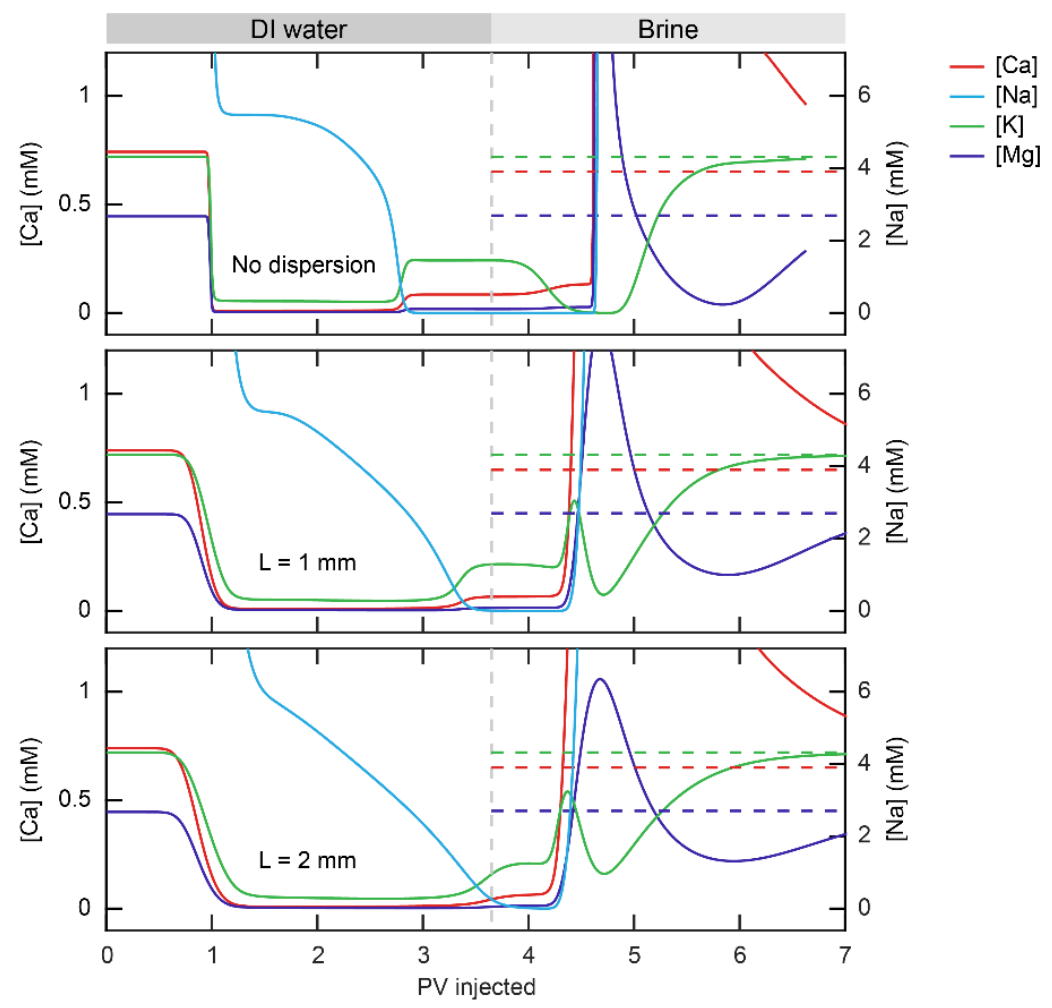

Figure S8. Elemental concentrations during the injection of DI water followed by brine for different dispersivity values. The CEC value is fixed at $0.20 \mathrm{mmol} / 100 \mathrm{~g}$. 


\section{Concentration profiles along the core length}

Figure S9 shows how the elemental concentrations and the occupation of the EDL along the core length (expressed as a percentage for each cation) vary as a function of the injected volume. The different steps are discussed below.
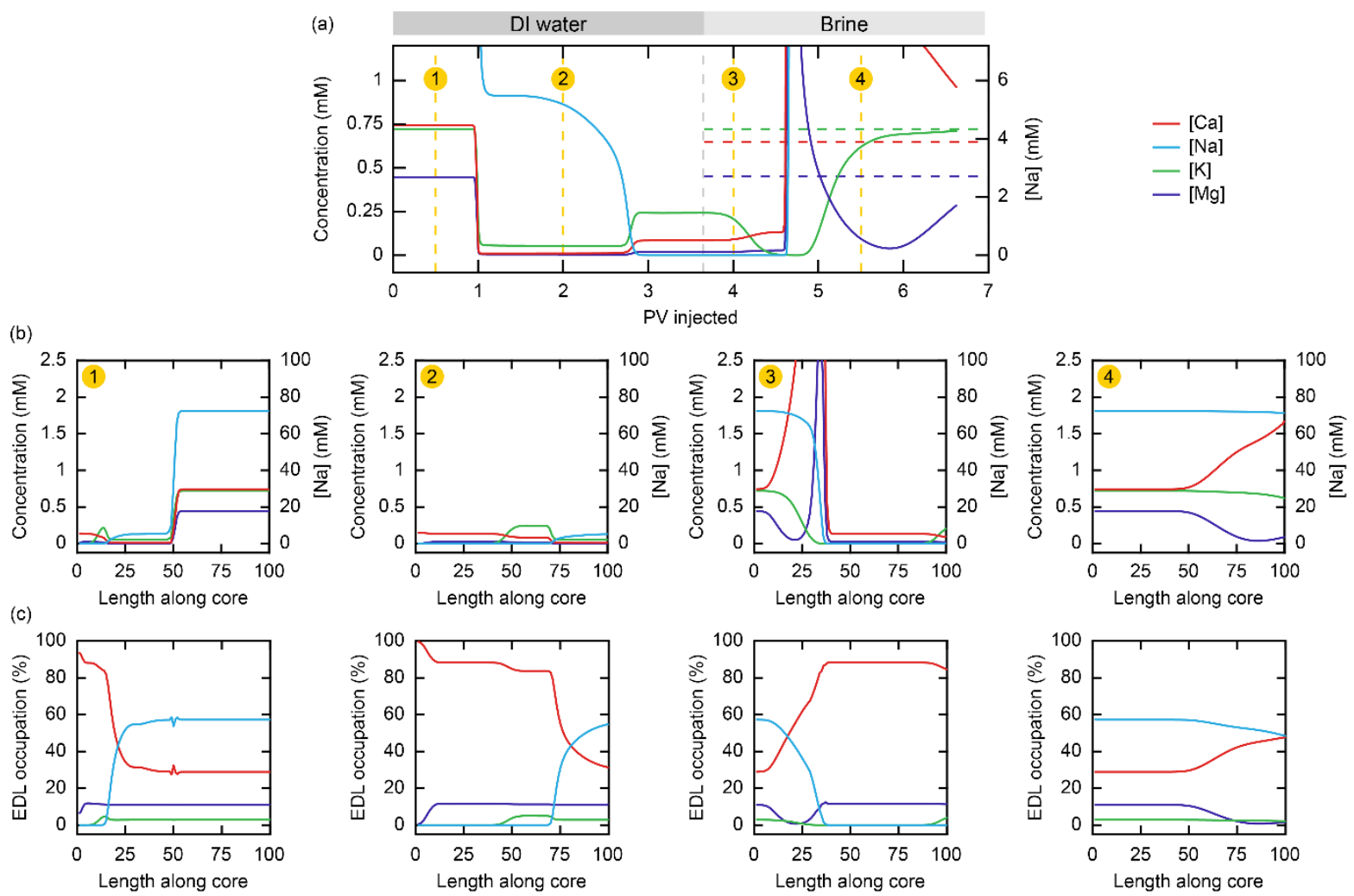

Figure S9. (a) Modelled elemental concentrations vs. pore volumes injected. (b) Elemental concentrations and (c) occupation of the EDL along the core length at times indicated by the numbers $1-4$.

Initially, the core is in equilibrium with the brine. Because of the high $\left[\mathrm{Na}^{+}\right] /\left[\mathrm{Ca}^{2+}\right]$ ratio $(\sim 111)$, most of the negative charge on the rock surface is screened by $\mathrm{Na}^{+}$. A small amount of calcite dissolves near the core inlet, causing the $\mathrm{pH}$ and $\mathrm{Ca}$ concentration to be slightly higher than in the injected brine. 
The injected DI water contains a small amount of $\mathrm{Na}^{+}$to increase the $\mathrm{pH}$ to 9.0 , but no $\mathrm{Ca}^{2+}, \mathrm{Mg}^{2+}$ or $\mathrm{K}^{+}$. Some calcite dissolves near the core inlet to maintain rock-brine equilibrium, bringing a small amount of $\mathrm{Ca}^{2+}$ and $\mathrm{CO}_{3}{ }^{2-}$ into solution (the latter being responsible for the increase in $\mathrm{pH}$ ). The $\left[\mathrm{Na}^{+}\right] /\left[\mathrm{Ca}^{2+}\right]$ ratio is now much smaller than before and as a result, most of the $\mathrm{Na}^{+}$in the EDL is exchanged for $\mathrm{Ca}^{2+}$. This mechanism is responsible for the $\mathrm{Na}^{+}$concentration not reaching zero until about $3 \mathrm{PV} . \mathrm{Mg}^{2+}$ and $\mathrm{K}^{+}$are also exchanged for $\mathrm{Ca}^{2+}$ as their concentrations are zero during the injection of DI water. After many pore volumes of DI water, the surface charge is almost entirely screened by $\mathrm{Ca}^{2+}$. Note that $3.65 \mathrm{PV}$ is not enough to reach this state as in particular the exchange of $\mathrm{Mg}^{2+}$ and $\mathrm{Ca}^{2+}$ occurs slowly.

When brine is injected, the initial $\left[\mathrm{Na}^{+}\right] /\left[\mathrm{Ca}^{2+}\right]$ ratio is restored. The loaded $\mathrm{Ca}^{2+}$ is rapidly exchanged for $\mathrm{Na}^{+}$, giving rise to a large peak in $[\mathrm{Ca}]$. The peak originates from a concentration build-up at the propagation front, as the injected brine encounters an EDL that is loaded with nearly $90 \% \mathrm{Ca}^{2+}$ while the equilibrium (rock-brine) value is close to $30 \% . \mathrm{Mg}^{2+}$ ions are also displaced from the EDL due to the high $\mathrm{Ca}^{2+}$ concentration at the propagation front, giving rise to a peak in $[\mathrm{Mg}]$ in the effluent. The $\mathrm{Mg}$ concentration then falls below the injection level because the sites in the EDL are refilled. 


\section{Surfactant adsorption experiments}

\section{Reproducibility}

Two surfactant adsorption experiments were performed to investigate reproducibility. In the first experiment, a 2 PV surfactant slug was followed by 3 PV brine and 10 PV brine:IPA. In the second experiment, a $3 \mathrm{PV}$ surfactant slug was followed by 4 PV brine and 10 PV brine:IPA. The curves are compared in Figure S10 with different offsets (0, 1, 2 PV) to show the overlap of the curves at three moments: at surfactant breakthrough, when the surfactant is displaced by the brine, and when the adsorbed surfactant is produced. The experiment is highly reproducible, indicating that the properties of the core are not significantly affected by the injected chemicals.
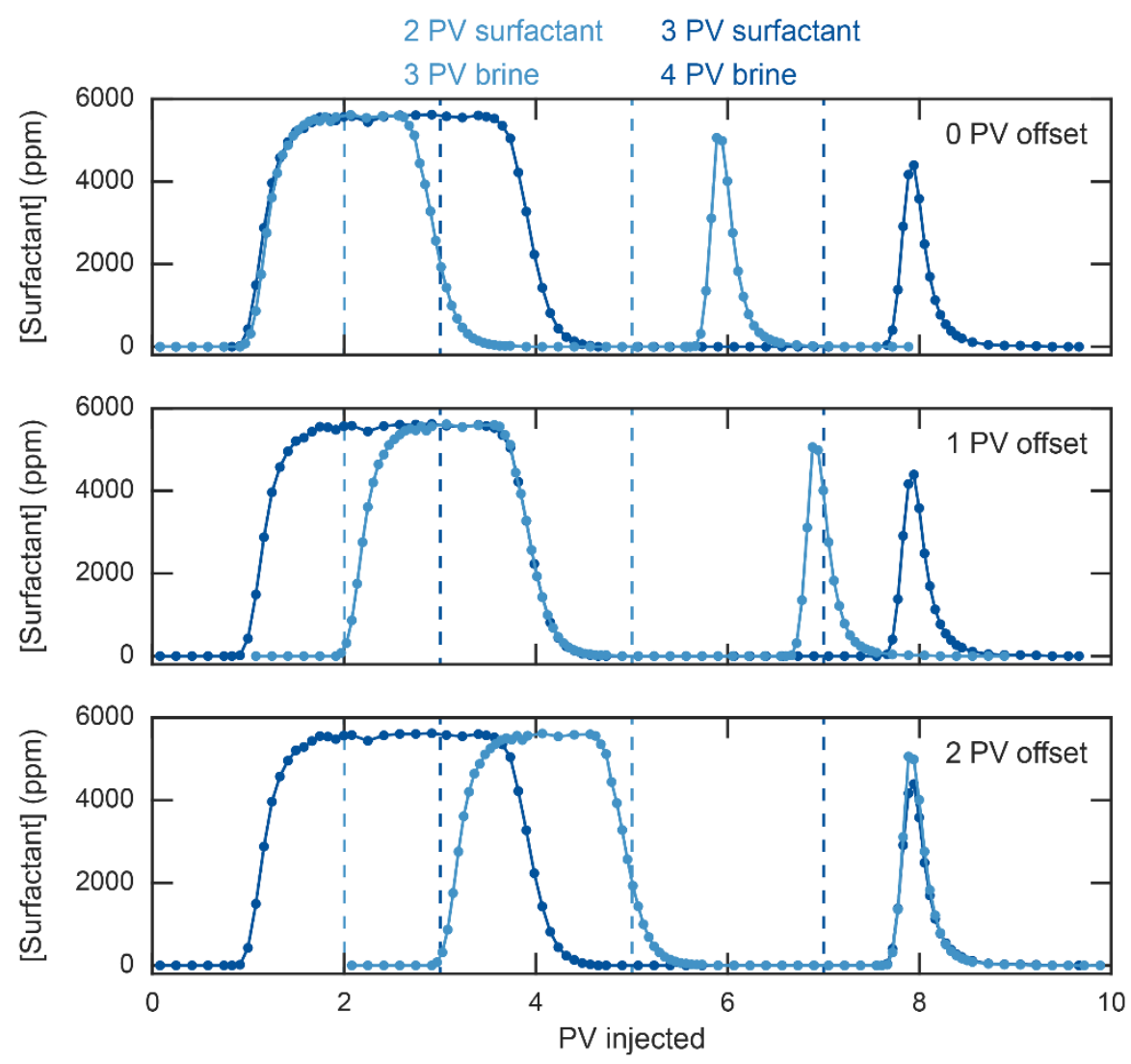

Figure S10. Surfactant concentrations during Experiments 1 and 2. The three panels show three different offsets of Experiment 2: 


\section{Concentration profiles along the core length: surfactant injection}
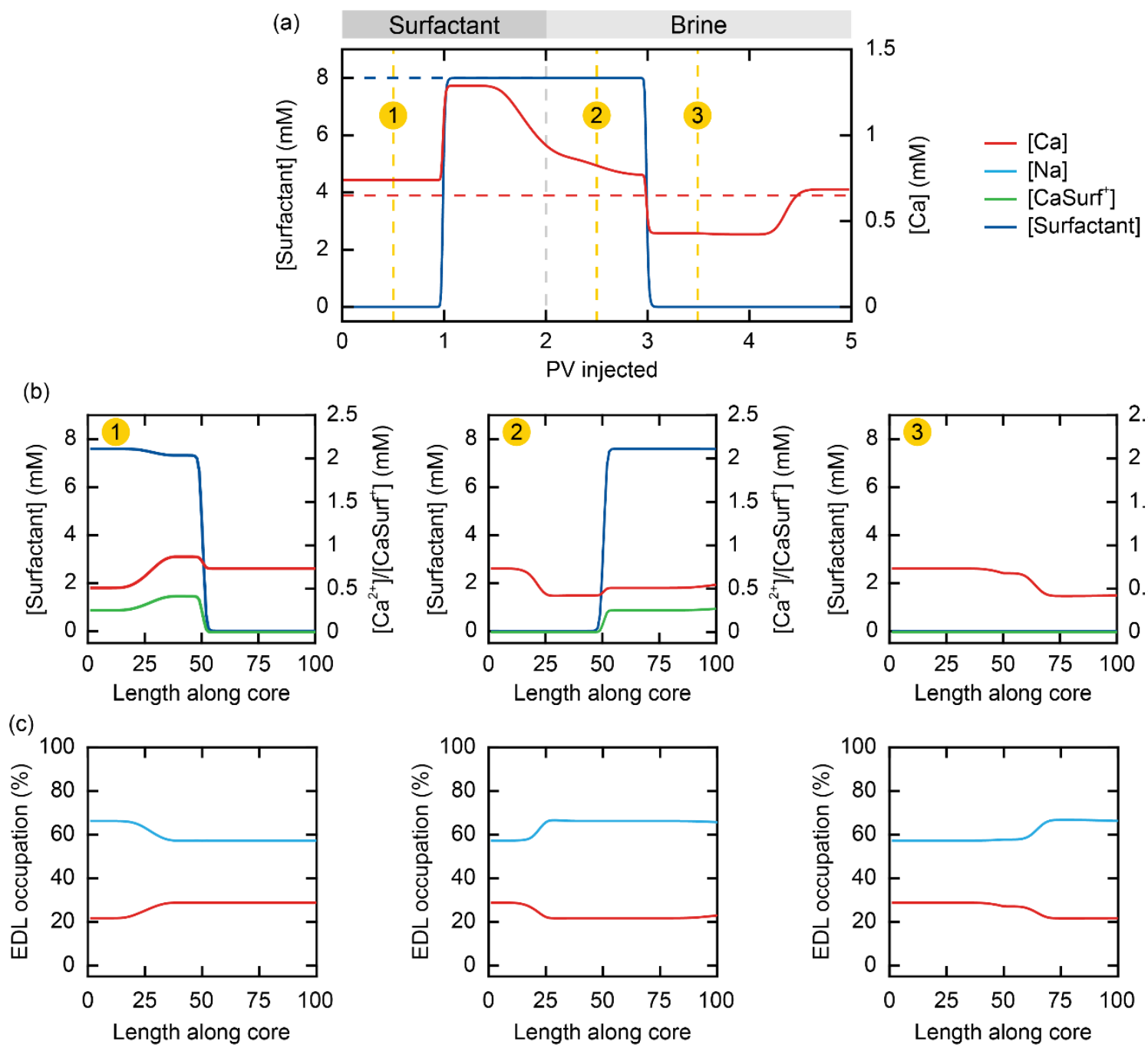

(d)

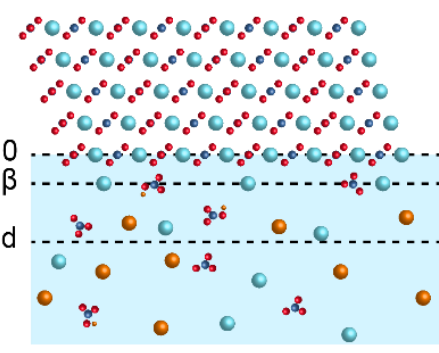

Rock in equilibrium with brine
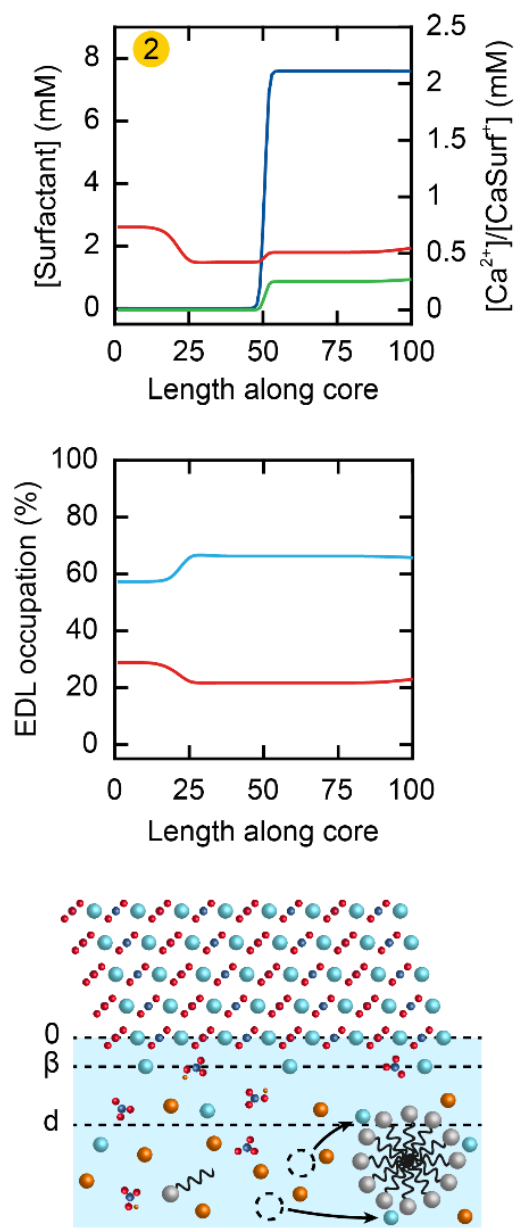

Surfactant complexes $\mathrm{Ca}^{2+}, \mathrm{Mg}^{2+}$ EDL: $\mathrm{Ca}^{2+}, \mathrm{Mg}^{2+}$ exchanged for $\mathrm{Na}^{+}$
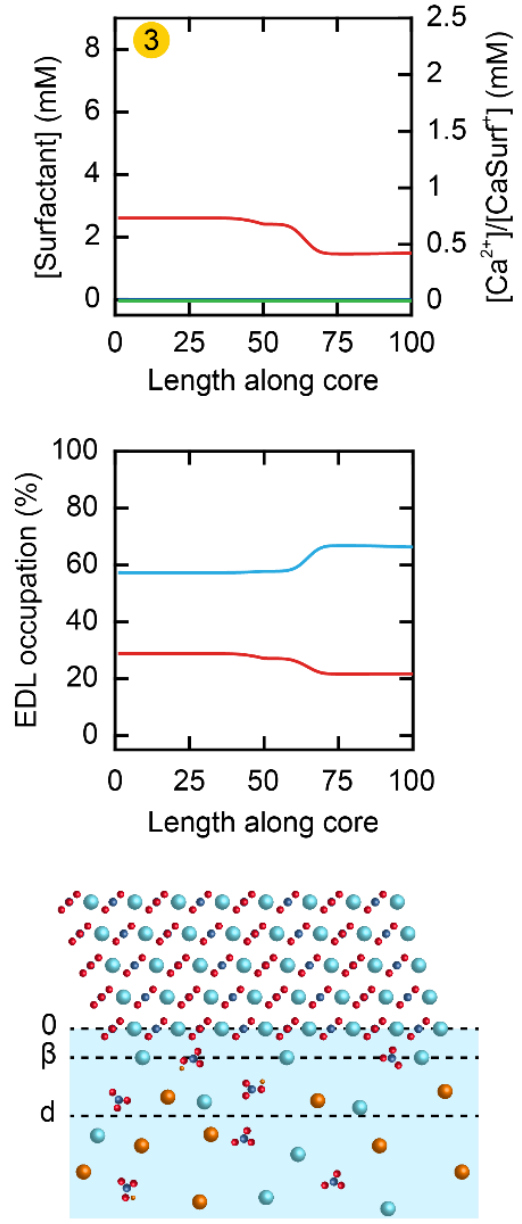

Rock-brine equilibrium restored EDL: $\mathrm{Na}^{+}$exchanged for $\mathrm{Ca}^{2+}, \mathrm{Mg}^{2+}$

Figure S11. (a) Modelled elemental concentrations vs. pore volumes injected. (b) Elemental concentrations and (c) occupation of the EDL along the core length at times indicated by the numbers 1-3. (d) Schematic showing the mechanisms that give rise to the features in the elemental concentration profiles. 


\section{Concentration profiles along the core length: surfactant + PAA injection}

(b)

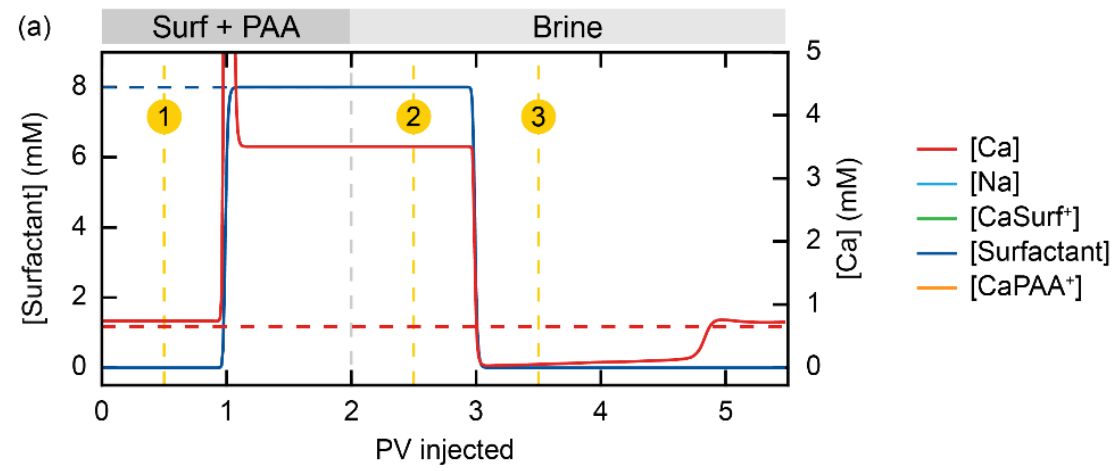

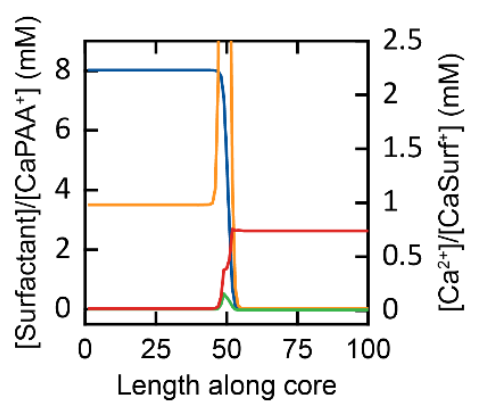

(c)

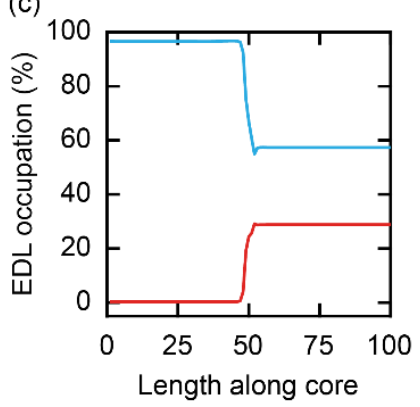

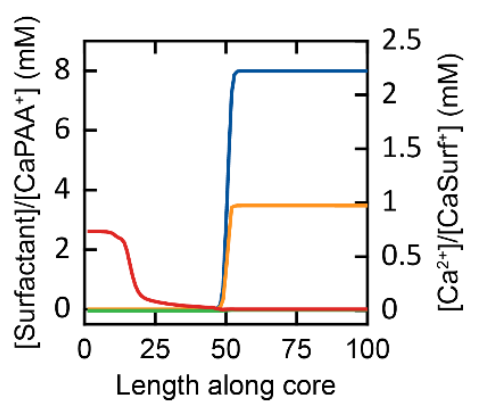
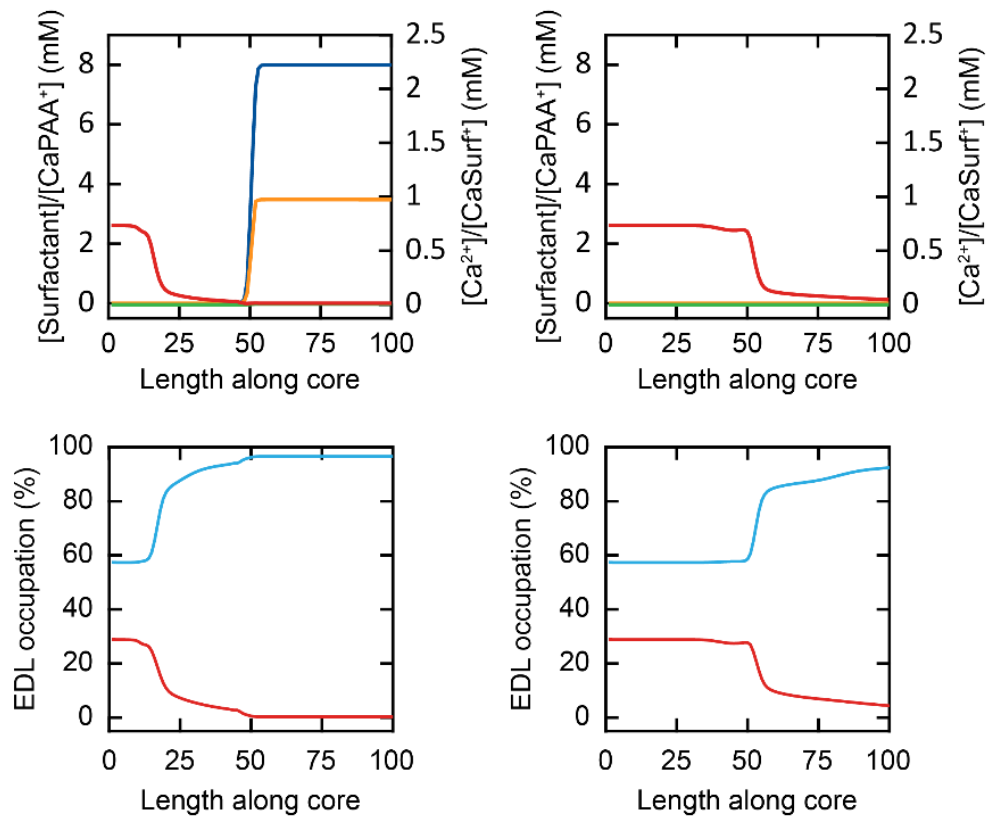

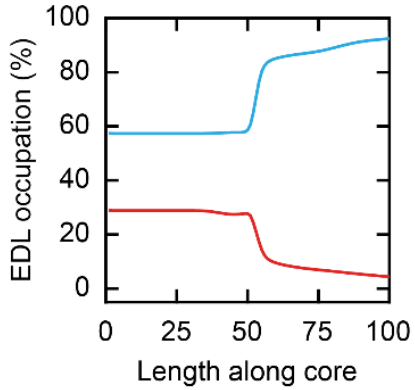

Figure S12. (a) Modelled elemental concentrations vs. pore volumes injected. (b) Elemental concentrations and (c) occupation of the EDL along the core length at times indicated by the numbers 1-3. 


\section{Surfactant flooding experiments: complete dataset}

The surfactant, Ca concentration and pH are shown in Figure S13, Figure S14 and Figure S15.

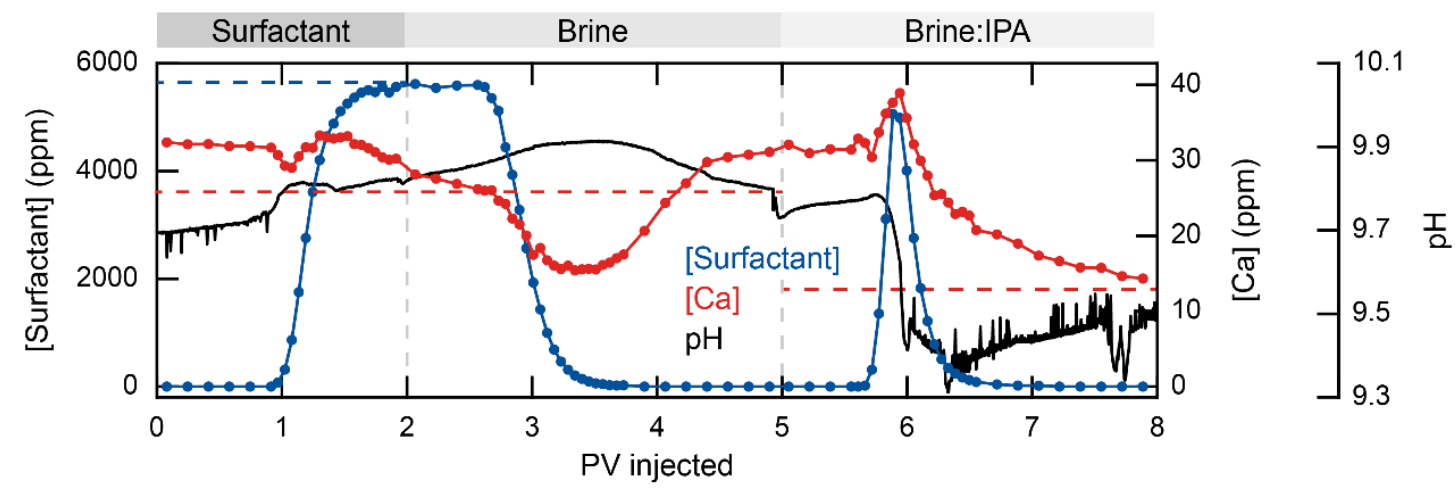

Figure S13. Experiment 1: Surfactant and Ca concentration and pH. Only 3 PV of the brine:IPA slug are shown.

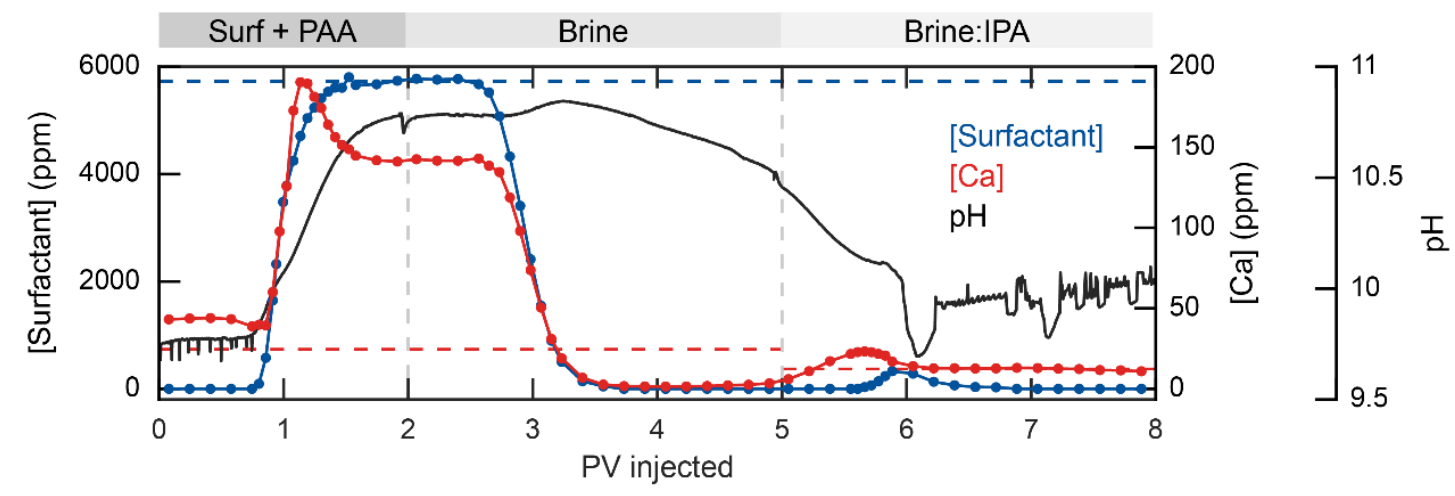

Figure S14. Experiment 2: Surfactant and Ca concentration and pH. Only 3 PV of the brine:IPA slug are shown.

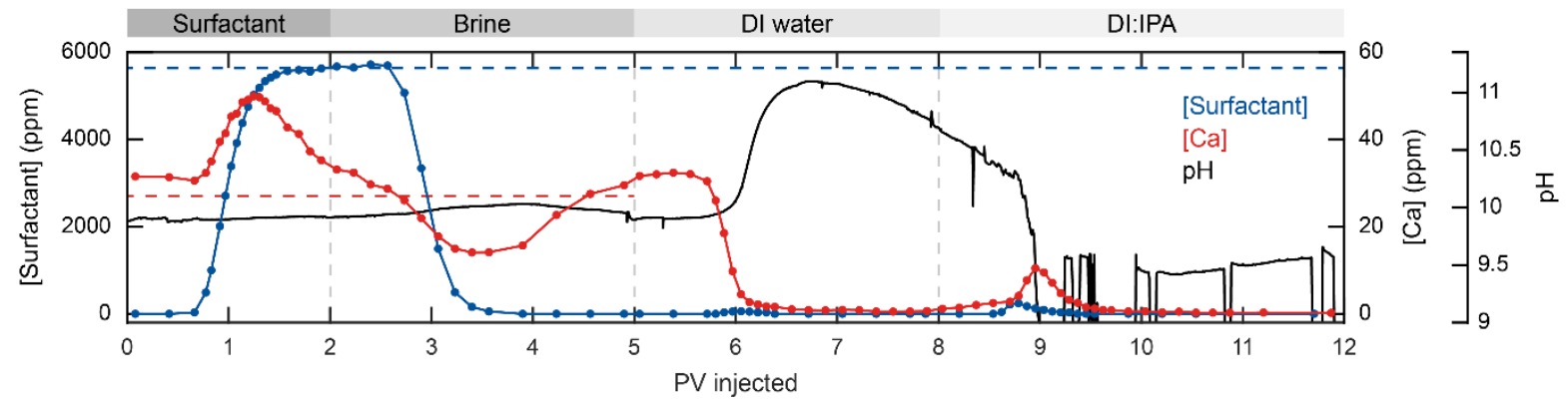

Figure S15. Experiment 4: Surfactant and Ca concentration and pH. Only 3 PV of the DI:IPA slug are shown. 


\section{Surfactant adsorption and Ca concentration}

The surfactant concentrations during experiments 1, 2 and 3 are shown together in Figure S16.

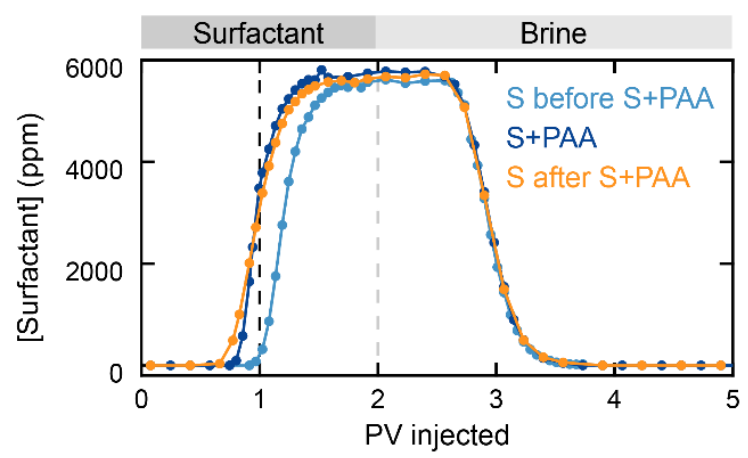

Figure S16. Surfactant concentrations during experiments 1, 2 and 3.

The Ca concentrations during experiments 1 and 3 are shown together in Figure S17.

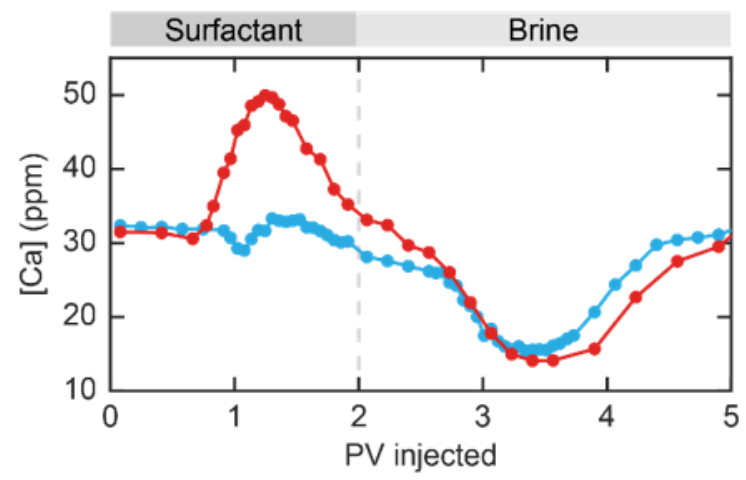

Figure S17. Ca concentration profile during experiment 1 (high adsorption, blue line) and 3 (low adsorption, red line). 


\section{Modelling surfactant adsorption}

Adsorption is modelled by including ion exchange reactions for $\mathrm{SurfCa}^{+}$and $\mathrm{SurfMg}^{+}$complexes.

The results for different equilibrium constants are shown in Figure S18. The delay of surfactant breakthrough increases with increasing values and with $\log \mathrm{K}=2.0$, a delay of $0.23 \mathrm{PV}$ is obtained. With this method, however, complete desorption of the surfactant occurs when brine is injected, which is at odds with the experimental data. Figure S18a shows that desorption delays the decrease of the surfactant adsorption and can even lead to a hump-like feature at high equilibrium constants, which are not observed in the experiments. Nevertheless, the first part of the modelled results can provide valuable insights into the adsorption mechanism, while the second part can provide insight into the behavior of the elemental concentrations and $\mathrm{pH}$ when the surfactant desorbs during brine:IPA injection.
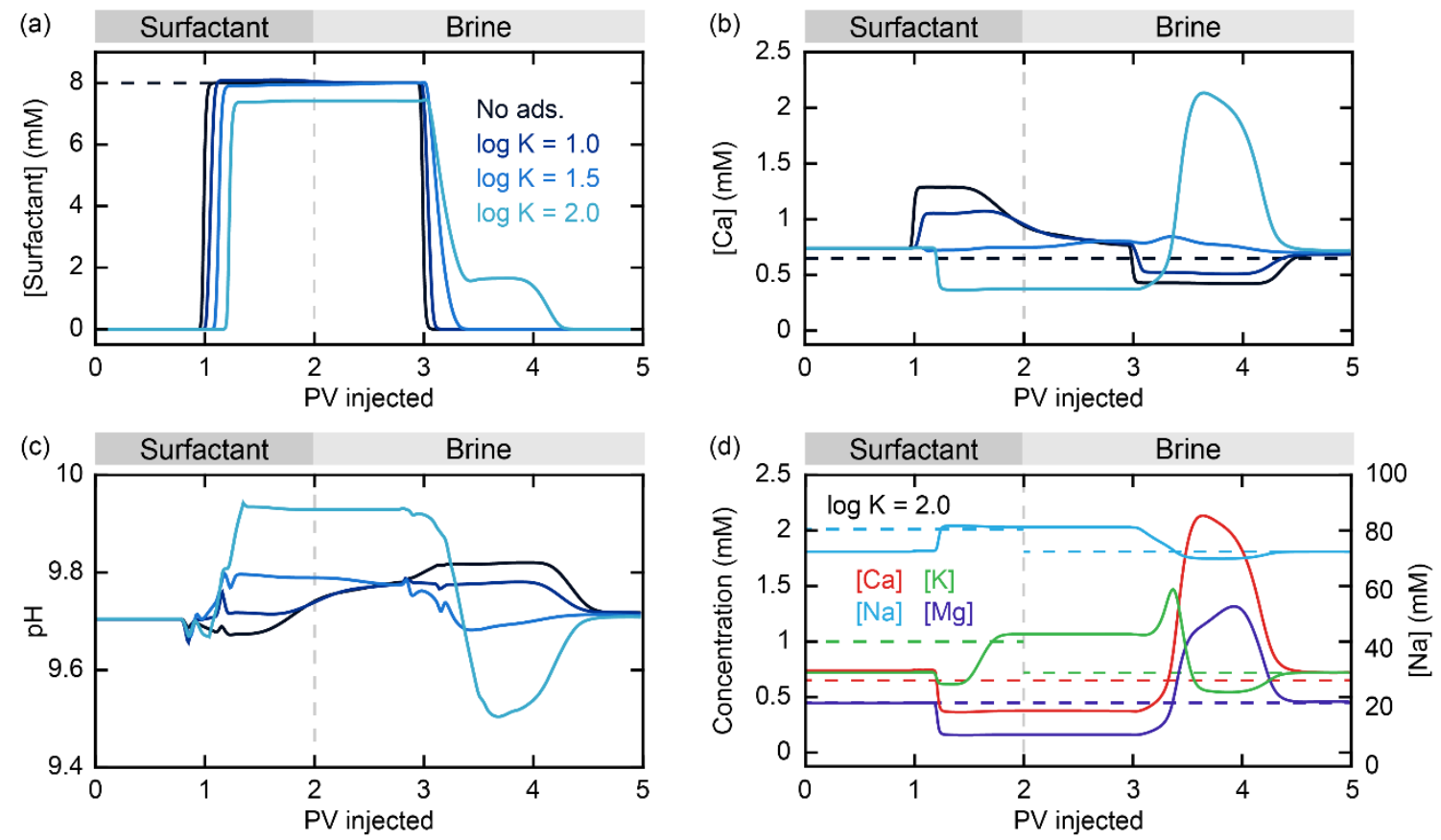

Figure S18. Modelled results including surfactant adsorption reactions with different equilibrium constants. (a) Surfactant concentration. (b) Ca concentration. (c) Numerically averaged pH values. (d) Elemental concentrations for log $K=2.0$. 
Adsorption: With increasing $\mathrm{K}$ values, the peak in $[\mathrm{Ca}]$ is suppressed and even falls below the injection level at $\log \mathrm{K}=2.0$. The lower $\mathrm{Ca}$ concentration is also observed experimentally. Including adsorption also causes the $\mathrm{pH}$ to rise at $1 \mathrm{PV}$, consistent with the experimental data.

Desorption: When the surfactant desorbs, peaks in $[\mathrm{Ca}]$ and $[\mathrm{Mg}]$ appear and the $\mathrm{pH}$ drops sharply, consistent with the experimental data. The slight drop of $[\mathrm{K}]$ below the injected level is also observed in the experiments.

\section{Modelling co-injection of surfactant and PAA}

We also investigated how the addition of PAA affects the surfactant concentration curve when surfactant adsorption is modelled through ion exchange, which is shown in Figure S19. The simulation was performed with an equilibrium constant of $\log \mathrm{K}=2.0$ for the adsorption reaction. The results show that the high affinity of PAA to complex divalent ions prevents the formation of surfactant-divalent ion complexes and therefore reduces adsorption to nearly zero. This implies that the adsorption of PAA does not need to be included to obtain low adsorption.

The calculated concentrations show that $3.9 \%$ of the PAA is in the form of $\mathrm{CaPAA}^{+}$or $\mathrm{MgPAA}^{+}$, which is more than enough to bind nearly all of the $\mathrm{Ca}^{2+}$ and $\mathrm{Mg}^{2+}$ ions. As a result, only $0.1 \%$ of the surfactant is in the form $\mathrm{SurfCa}^{+}$or $\mathrm{SurfMg}^{+}$(compared to $5.1 \%$ when injecting the surfactant alone). The 50 times lower concentration of surfactant complexes is therefore the main mechanism responsible for the reduction in surfactant adsorption during co-injection, while the low adsorption in the following experiment with surfactant only shows that a PAA pre-flush also reduced adsorption, likely by covering the rock surface. Despite this, ion exchange reactions occur as if the PAA is not adsorbed on the surface. 


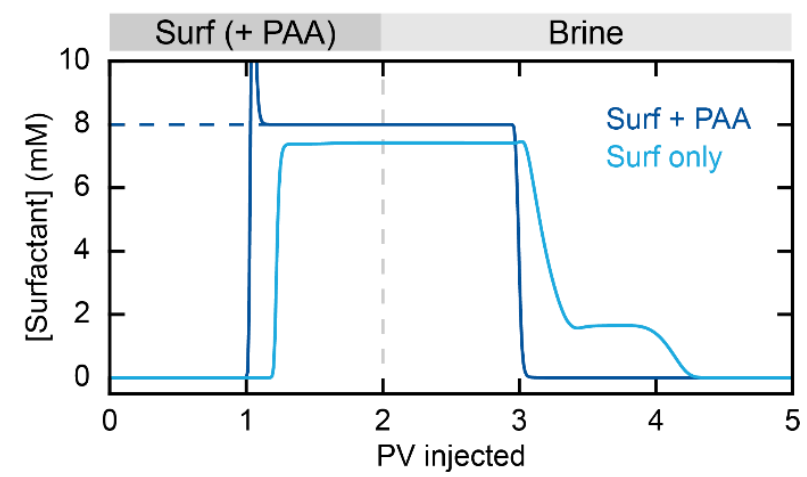

Figure S19. Co-injection of surfactant and 1\% PAA. Log $K=2.0$ for the surfactant adsorption reaction.

\section{Fluid compositions}

The solution compositions used for modelling are shown in the tables below. Table S2 shows the composition used for modelling the injection of the surfactant solution.

\begin{tabular}{|c|c|c|c|c|c|c|c|}
\hline $\begin{array}{c}\text { Injection } \\
\text { step }\end{array}$ & $\begin{array}{c}{[\mathrm{Na}]} \\
(\mathrm{mM})\end{array}$ & $\begin{array}{c}{[\mathrm{Cl}]} \\
(\mathrm{mM})\end{array}$ & $\begin{array}{c}{[\mathrm{Ca}]} \\
(\mathrm{mM})\end{array}$ & $\begin{array}{c}{[\mathrm{K}]} \\
(\mathrm{mM})\end{array}$ & $\begin{array}{c}{[\mathrm{Mg}]} \\
(\mathrm{mM})\end{array}$ & $\begin{array}{c}{[\text { Surfactant] }} \\
(\mathrm{mM})\end{array}$ & $\begin{array}{c}\text { [Polyacrylate] } \\
(\mathrm{mM})\end{array}$ \\
\hline Brine & 72.4 & 75.32 & 0.65 & 0.72 & 0.45 & - & - \\
\hline Surf. & 80.4 & 75.6 & 0.65 & 1.0 & 0.45 & 8.0 & - \\
\hline Brine & 72.4 & 75.32 & 0.65 & 0.72 & 0.45 & - & - \\
\hline
\end{tabular}

Table S2. Solution composition (surfactant only).

Table S3 shows the composition used for modelling the injection of the surfactant + PAA solution.

\begin{tabular}{|c|c|c|c|c|c|c|c|}
\hline $\begin{array}{c}\text { Injection } \\
\text { step }\end{array}$ & $\begin{array}{c}{[\mathrm{Na}]} \\
(\mathrm{mM})\end{array}$ & $\begin{array}{c}{[\mathrm{Cl}]} \\
(\mathrm{mM})\end{array}$ & $\begin{array}{c}{[\mathrm{Ca}]} \\
(\mathrm{mM})\end{array}$ & $\begin{array}{c}{[\mathrm{K}]} \\
(\mathrm{mM})\end{array}$ & $\begin{array}{c}{[\mathrm{Mg}]} \\
(\mathrm{mM})\end{array}$ & $\begin{array}{c}{[\text { Surfactant] }} \\
(\mathrm{mM})\end{array}$ & $\begin{array}{c}\text { [Polyacrylate] } \\
(\mathrm{mM})\end{array}$ \\
\hline $\begin{array}{c}\text { Brine } \\
\begin{array}{c}\text { Surf. }+ \\
\text { PAA }\end{array}\end{array}$ & 72.4 & 75.32 & 0.65 & 0.72 & 0.45 & - & - \\
\hline Brine & 72.4 & 75.78 & 0.65 & 1.18 & 0.45 & 8.0 & 100 \\
\hline
\end{tabular}

Table S3. Solution composition (surfactant + PAA). 


\section{Solution equilibrium reactions and equilibrium constants}

The used solution equilibrium reactions and associated constants are shown in Table S4.

\begin{tabular}{|c|c|c|}
\hline Reaction & log $\mathrm{K}$ & Units \\
\hline $\mathrm{H}_{2} \mathrm{O} \rightleftharpoons \mathrm{OH}^{-}+\mathrm{H}^{+}$ & $\begin{array}{c}\text { Calculated in } \\
\text { PHREEQC }\end{array}$ & $\mathrm{mol}^{2} \mathrm{~L}^{-2}$ \\
\hline $\mathrm{CO}_{3}^{2-}+\mathrm{H}^{+} \rightleftharpoons \mathrm{HCO}_{3}^{-}$ & 10.329 & $\mathrm{~L} \mathrm{~mol}^{-1}$ \\
\hline $\mathrm{CO}_{3}^{2-}+2 \mathrm{H}^{+} \rightleftharpoons \mathrm{CO}_{2}+\mathrm{H}_{2} \mathrm{O}$ & 16.681 & $\mathrm{~L}^{2} \mathrm{~mol}^{-2}$ \\
\hline $\mathrm{Ca}^{2+}+\mathrm{H}_{2} \mathrm{O} \rightleftharpoons \mathrm{CaOH}^{+}+\mathrm{H}^{+}$ & -12.78 & $\mathrm{~mol} \mathrm{~L}^{-1}$ \\
\hline $\mathrm{CaCO}_{3} \rightleftharpoons \mathrm{Ca}^{2+}+\mathrm{CO}_{3}^{2-}$ & -8.48 & $\mathrm{~L}^{2} \mathrm{~mol}^{-2}$ \\
\hline $\mathrm{Ca}^{2+}+\mathrm{CO}_{3}^{2-}+\mathrm{H}^{+} \rightleftharpoons \mathrm{CaHCO}_{3}^{+}$ & 11.435 & $\mathrm{~L}^{2} \mathrm{~mol}^{-2}$ \\
\hline $\mathrm{Mg}^{2+}+\mathrm{H}_{2} \mathrm{O} \rightleftharpoons \mathrm{MgOH}^{+}+\mathrm{H}^{+}$ & -11.44 & $\mathrm{~mol} \mathrm{~L}^{-1}$ \\
\hline $\mathrm{Mg}^{2+}+\mathrm{CO}_{3}^{2-} \rightleftharpoons \mathrm{MgCO}_{3}$ & 2.98 & $\mathrm{~L}^{2} \mathrm{~mol}^{-2}$ \\
\hline $\mathrm{Mg}^{2+}+\mathrm{H}^{+}+\mathrm{CO}_{3}^{2-} \rightleftharpoons \mathrm{MgHCO}_{3}^{+}$ & 11.399 & $\mathrm{~L}^{2} \mathrm{~mol}^{-2}$ \\
\hline $\mathrm{Na}^{+}+\mathrm{H}_{2} \mathrm{O} \rightleftharpoons \mathrm{NaOH}+\mathrm{H}^{+}$ & -14.180 & $\mathrm{~mol} \mathrm{~L}^{-1}$ \\
\hline $\mathrm{K}^{+}+\mathrm{H}_{2} \mathrm{O} \rightleftharpoons \mathrm{KOH}+\mathrm{H}^{+}$ & -14.180 & $\mathrm{~mol} \mathrm{~L}^{-1}$ \\
\hline
\end{tabular}

Table S4. Solution equilibrium reactions. 